\title{
COMMENTARY
}

\section{Endothelial progenitors in sepsis: vox clamantis in deserto?}

\author{
Michael S Goligorsky* \\ See related research by Patschan et al., http://ccforum.com/content/15/2/R94
}

\begin{abstract}
In this issue of Critical Care, Patschan and colleagues present a study of endothelial progenitor cells (EPCS) in patients with sepsis. The importance of this study is in focusing attention on several frequently ignored aspects of sepsis. Among those are the phenomenon of microvascular dysfunction, which is potentially responsible for profound metabolic perturbations at the tissue level, and the role of endothelial progenitors in repair processes. Other important aspects of the study are the regenerative capacity of mobilized EPCs and the dissociation between the numerical value and clonogenic competence. Attempting to restore the competence to EPCs should be a priority in the future.
\end{abstract}

In this issue of Critical Care, Patschan and colleagues [1] present a study of endothelial progenitor cells (EPCs) in patients with sepsis. The data convincingly demonstrate that the levels of circulating EPCs in septic patients are elevated and that this phenomenon is independent of the presence of acute renal failure. Moreover, the functional competence of circulating EPCs, as judged by the clonogenic assay, is reduced in sepsis, whereas the levels of circulating pro-angiogenic or EPC-mobilizing factors (like vascular endothelial growth factor, stem cell-derived factor-1, and angiopoietin-2) or both are higher in sepsis than in the control healthy population. It is my belief that the importance of this study is in focusing attention on several frequently ignored aspects of sepsis. These are detailed below.

Systemic macrovasculopathy manifesting as a drop in blood pressure has attracted much attention. By comparison, the phenomenon of microvascular dysfunction, which is potentially responsible for profound metabolic

*Correspondence: michael_goligorsky@nymc.edu

Departments of Medicine, Pharmacology, and Physiology, Renal Research Institute, New York Medical College, 15 Dana Road, Valhalla, NY 10595, USA perturbations at the tissue level, is more surreptitious, despite the fact that it is responsible for the eventual multi-organ failure [2]. By most accounts, sepsis-induced development of vasculopathy is significantly hampered by the default response to stress: mobilization of stem and progenitor cells that, in part, restore damaged vasculature [3]. By extension, a physician should be alerted to the fact and be alarmed when a septic patient does not boost the number of circulating EPCs. This can occur in patients with a preexisting chronic cardiovascular or renal disease or in older patients and, in any of these cases, could result in the exhaustion of a pool of readily recruitable EPCs. This prediction will require future detailed analysis of the causes and consequences of the hampered surge in circulating EPCs.

Regenerative capacity and the dissociation between the numerical value and clonogenic competence represent the crux of the problem in sepsis. Reactive oxygen species, proinflammatory cytokines and chemokines, adrenergic stimulation, and other factors compromise various aspects of stem cell functions, their mobilization, niche properties, engraftment, and signaling, all of which result in the exhaustion of the EPC pool or incompetence of EPCs or both [4]. In addition, aging is the most common cause of stem cell dysfunction [5]. Therefore, the end result of the numerical and clonogenic dissociation of stem cell response to sepsis, the proverbial vox clamantis in deserto, is a complex integral of their quantity and quality. Hence, one of the potential clinical goals could be restoring stem cell competence.

While the fact of sepsis-induced mobilization of EPCs does not seem to cause dispute [6], the definition of EPCs and the significance of their recruitment are contentious subjects. The origins of these cells, their homogeneity, and identification markers are but a few unsettled issues as discussed by the authors, who in the midst of the existing debates have elected rational strategies to assess EPCs numerically and functionally. What I perceive as an even more serious challenge, however, is the fact that, along the path(s) from the quiescence of a niche environment to the re-programming signals in the circulation and target tissues, these cells are continuously changing 
their character and marker make-up. A single measurement provides but a snapshot of rapidly changing events in the context of evolving pathophysiological presentations of sepsis. It is necessary to perform fate tracing of various stem and progenitor cells in experimental animals subjected to a model of sepsis to gain insights into the pathways from niches to tissues, expression of various markers, and potential bifurcations along the path in order to test the validity of such findings in human disease.

I hope that the authors, having demonstrated EPC responses to sepsis, will conduct longitudinal numerical and functional testing of EPCs with the concomitant analysis of clinical presentations and outcomes in a large cohort of patients with sepsis. It is important to examine EPC responses in septic patients of various ages, in males and females, in patients with a preexisting chronic kidney or cardiovascular disease and those without them, and in patients who are immune-competent and those who are not.

Abbreviation

EPC, endothelial progenitor cell.

\section{Competing interests}

The author declares that he has no competing interests.

Published: 25 March 2011

\section{References}

1. Patschan SA, Patschan D, Temme J, Korsten P, Wessels JT, Koziolek M, Henze E, Mueller GA: Endothelial progenitor cells (EPC) in sepsis with acute renal dysfunction (ARD). Crit Care 2011, 15:R94.

2. Balestra GM, Legrand M, Ince C: Microcirculation and mitochondria in sepsis: getting out of breath. Curr Opin Anaesth 2009, 22:184-190.

3. Rafat N, Hanusch C, Brinkkoetter PT, Schulte J, Brade J, Zijlstra JG, van der Woude FJ, van Ackern K, Yard BA, Beck GCh: Increased circulating endothelial progenitor cells in septic patients: correlation with survival. Crit Care Med 2007, 35:1677-1684.

4. Goligorsky MS: Stem cell injury and premature senescence. In Regenerative Nephrology. Edited by Goligorsky MS. Amsterdam: Academic Press; 2010:275-288.

5. Rauscher FM, Goldschmidt-Clermont PJ, Davis BH, Wang T, Gregg D, Ramaswami P, Pippen AM, Annex BH, Dong C, Taylor DA: Aging, progenitor cell exhaustion, and atherosclerosis. Circulation 2003, 108:457-463.

6. Cribbs SK, Martin GS, Rojas M: Monitoring of endothelial dysfunction in critically ill patients: the role of endothelial progenitor cells. Curr Opin Crit Care 2008, 14:354-360.

doi:10.1186/cc10105

Cite this article as: Goligorsky MS: Endothelial progenitors in sepsis: vox clamantis in deserto? Critical Care 2011, 15:142. 